\section{América Latina en el marco de la reconfiguración hegemónica mundial: el avance estratégico de China en la región en el siglo XXI}

\author{
Latin America in the Setting of the Global, Hegemonic \\ Reconfiguration: China's Strategic Advance in the Region \\ in the 21st Century
}

\section{América Latina dentro do marco da reconfiguração hegemônica global: o avanço estratégico da China na região no século XXI}

\author{
Ada Celsa Cabrera García ${ }^{1}$ \\ Giuseppe Lo Brutto²
}

DOI: 10.5752/P.2317-773X.2019v7.n3.p51

Recibido el 05 de julio de 2018

Aprobado el 14 de noviembre de 2018

\section{RESUMEN}

El propósito de este trabajo es analizar el momento que vive la región latinoamericana en el actual contexto de reconfiguración hegemónica de la economía mundial. Este último se expresa en el conjunto de tensiones y cuestionamientos que experimenta el sistema interestatal de posguerra, sobre el cual se erigió y consolidó el liderazgo hegemónico estadounidense. Al mismo tiempo, se observa el auge de China como un actor que, incluso sin renunciar a las instituciones del mencionado sistema, desarrolla y promueve nuevas dinámicas de interacción entre países que no obedecen a los principios del consenso interestatal expresado en la Carta Magna de las Naciones Unidas (NN UU). Ante tal escenario, América Latina (AL) se entiende como un territorio en disputa en el que se cruzan, por un lado, los intereses de Estados Unidos (EE UU) buscando mantener su rol como centro hegemónico y, por el otro, las estrategias de expansión de China en las que se observa un cada vez mayor protagonismo en Latinoamérica a partir de este milenio.

Palabras clave: Economía Mundial; Hegemonía; Sistema Interestatal; América Latina; China.

\section{ABSTRACT}

The purpose of this paper is to analyze the current situation of the Latin American region in the context of hegemonic reconfiguration of world economy. The latter is expressed in the combination of tensions and questioning that undergoes the post-war interstate system, on which the hegemonic leadership of the United States of America (US) was built and consolidated. At the same time, the
1. Doctora en Sociologia por el Instituto de Ciencias Sociales y Humanidades "Alfonso Velez Pliego" (ICSyH) de la Benemerita Universidad Autonoma de Puebla (BUAP). Profesora investigadora de la Facultad de Economía, BUAP. Pertenece al Sistema Nacional de Investigadores de Mexico (SNI), nivel I. Miembro del Cuerpo Académico en Consolidación "Análisis Económico", BUAP-CA 130. Forma parte del grupo de investigación en Cooperación Sur-Sur e Integraciones Regionales de REEDES. Ciudad y país de residencia: Puebla, México. Número ORCID http://orcid org/0000-0003-0272-0987. Contacto: adacelsa.cabrera@correo.buap.mx (iD)

2. Doctor en Economía Política del Desarrollo por la Facultad de Economía de la Benemérita Universidad Autónoma de Puebla (BUAP), México. Profesor-investigador del Posgrado en Sociología del Instituto de Ciencias Sociales y Humanidades "Alfonso Vélez Pliego" (ICSyH), BUAP. Pertenece al Sistema Nacional de Investigadores (SNI), nivel I. Miembro del Cuerpo Académico Consolidado "Sociología Política y del Desarrollo", BUAP-CA 195. Coordinador del Grupo de Investigación en Cooperación Sur-Sur e Integraciones Regionales de REEDES. Ciudad y país de residencia: Puebla, México. Número ORCID https://orcid. org/0000-0002-8126-5013. Contacto: giuseloby@msn.com (1D) 
3. Esta dinámica queda ampliamente desarrollada en el estudio que Giovanni Arrighi (1999) realiza sobre el desarrollo de la economía mundial capitalista. El autor propone la categoría de "ciclos sistémicos de acumulación" (CSA). Es en el segundo CSA, el holandés, que se observa la existencia de un Estado que lidera la dinámica de acumulación

a escala mundial. La hegemonía de Holanda fue precisamente posible por los acuerdos de la Paz de Westfalia, a igual que la británica, mientras que la estadounidense estuvo acompañada por la firma de la Carta Magna de las

NN UU.

4. Giovanni Arrighi (1999) observa la interacción de dos lógicas fundamentales en los procesos de configuración y reconfiguración que ha experimentado el sistema interestatal: la capitalista y la territorialista. La primera se expresa en la búsqueda por ampliar el dominio

territorial encabezado en términos históricos por los principales imperios coloniales europeos. La acumulación de capital fue el principal medio para

alcanzar dicho fin, pues el financiamiento para lograr el control y dominio político de nuevos territorios procedió de las principales agencias capitalistas

de la época. La expansión territorial también traía consigo el control de rutas comerciales y la extracción de recursos y mercancías, cuyos beneficios tendían

a concentrarse en manos de quienes

tenían por objeto la acumulación de capital. Estos últimos, se valían del control que la dominación territorial ejercía políticamente sobre tierras y poblaciones para garantizar su principal objetivo, la reproducción del capital. Así, la lógica de la dominación capitalista invierte los fines y los medios respecto de la lógica territorialista, el objetivo es el de acumular capital y un medio para lograrlo es el dominio de territorios. rise of China is seen as an actor that, even without renouncing the institutions of the mentioned system, develops and promotes new dynamics of interaction between countries that do not obey the principles of interstate consensus expressed in the United Nations Magna Carta (NN UU). Given such a scenario, Latin America (AL) is understood as a disputed territory where coexist, on the one hand, the interests of the US are seeking to maintain its role as an hegemonic center and, on the other, the expansion strategies of China in which there is an increasing prominence in LA started in this millennium.

Keywords: World Economy; Hegemony; Interstate System; Latin America; China

\section{Resumo}

O objetivo deste trabalho é analisar o momento vivido pela região latino-americana no atual contexto de reconfiguração hegemônica da economia mundial. Este último é expresso no conjunto de tensões e questionamentos que experimenta o sistema interestatal do pós-guerra, sobre o qual a liderança hegemônica estadunidense foi erguida e consolidada. Ao mesmo tempo, observa-se o auge da China como ator que, mesmo sem renunciar às instituições do sistema mencionado, desenvolve e promove novas dinâmicas de interação entre países que não obedecem aos princípios do consenso interestatal expresso na Carta Magna da Nações Unidas (NN UU). Diante desse cenário, a América Latina (AL) é entendida como um território em disputa no qual se cruzam, por um lado, os interesses dos Estados Unidos (EUA), buscando manter seu papel de centro hegemônico e, por outro, as estratégias de expansão da China na qual se observa cada vez mais, um maior protagonismo na América Latina a partir deste milênio.

Palavras-chave: Economia mundial; Hegemonia; Sistema Interestadual; América Latina; China.

Introducción

Hablar sobre las relaciones entre Estados nos remonta a las interpretaciones que existen sobre el sistema interestatal y las expresiones que este ha adquirido en la historia, así como sobre la existencia de centros hegemónicos que lo lideran. De manera concreta, sus orígenes se encuentran en la Paz de Westfalia de 1648 y, más recientemente, en la firma de la Carta Magna de las NN UU de $1945^{3}$. Esos momentos de fundación y reconfiguración ponen en relevancia que la decadencia de un centro hegemónico y la posibilidad de surgimiento de uno o varios sucesores hasta ahora han estado envueltos en un clima de tensiones e incluso desbordamiento de los postulados del sistema interestatal previo.

La paz de Westfalia, que articuló el primer acuerdo interestatal, no se dio entre los modernos Estados capitalistas, sino entre los Estados absolutistas de los que derivarían, en gran medida, elementos para la conformación de los modernos Estados-nación. En cambio, la Carta de las NN UU dio un giro al sistema interestatal modificando a los actores fundamentales del derecho internacional y frenando las capacidades de los Estados-nación en relación a las existentes en el anterior acuerdo. El reconocimiento de los individuos y de las minorías como sujetos del derecho internacional cambió básicamente los conceptos de soberanía y responsabilidad entre un pacto y otro. Ambos momentos históricos posibilitaron un marco en el que la lógica de dominación capitalista y la de dominación territorialista ${ }^{4}$ mantuvieron una relación de coexistencia en la que en determinados momentos una ha sido superior a la otra. 
Las contradicciones que vive el actual sistema interestatal muestran cómo dentro de la lógica capitalista el recurso a la guerra para dominar territorios ricos en recursos naturales es cada vez más evidente, poniendo en discusión la vigencia de la Carta de NN UU.

Este trabajo surge precisamente de observar que quienes han suscrito los principios de la Carta de las NN UU ejecutan acciones que no precisamente se corresponden con los postulados de la misma. Un ejemplo de ello es el caso de las intervenciones militares llevadas a cabo sin la venia del Consejo de Seguridad de NN UU5.

El presente estudio se enmarca dentro de la primera de las cuatro controversias que se entrelazan en el trabajo de Arrighi y Silver (2001) sobre el futuro de la economía política mundial, es decir, "al cambiante equilibrio de poder entre Estados, y en particular si es o no probable que surja un nuevo estado hegemónico" (ARRIGHI; SILVER, 2001, p. 11). A partir de ello, el artículo evidencia tres potenciales situaciones: a) el sistema interestatal de la segunda posguerra superará las tensiones y seguirá vigente manteniendo a Estados Unidos como líder; b) un nuevo sistema interestatal se está gestando bajo el liderazgo ${ }^{6}$ que podría estar representado por China; c) ambos sistemas coexisten en un momento que podríamos considerar de "caos sistémico"” (ARRIGHI; SILVER, 2011, p. 37).

Es precisamente en ese contexto que nos preguntamos por el lugar que $\mathrm{AL}$ adquiere en el actual momento de reconfiguración hegemónica mundial. En este sentido, el escenario muestra una disputa por la región a partir de la clara estrategia de penetración político-económica que ha hecho que el gigante asiático se sume a la presencia mantenida durante décadas por los EE UU en AL.

A tal propósito, se realiza un análisis sobre el momento que actualmente vive la región latinoamericana en el contexto de cambio que experimenta, en sus panoramas político y económico, al inscribirse dentro de un dinamismo de crisis global. Partimos de la propuesta de que las crisis recurrentes, que en los últimos años ha experimentado la economía mundial, han agudizado el momento de caos sistémico que ve a EE UU y a China como los dos actores principales en disputa por la hegemonía global. Por ello, las preguntas principales que intentamos responder son ¿Cómo se está dando el avance estratégico de China en AL en el siglo XXI frente a la reconfiguración hegemónica que vive la economía global? y, en la misma línea de trabajo ¿cuáles serían los elementos que permitirían constatar que se está gestando otro sistema interestatal que ve a China como su nuevo líder?

Nuestra hipótesis de trabajo es que China va construyendo un sistema interestatal alternativo que actualmente convive con el de EE UU en el sistema de NN UU y, en este sentido, AL se vuelve un actor estratégico para los fines de expansión del dragón asiático.

Construimos el argumento anterior a lo largo de las tres partes del trabajo que siguen a la presente introducción. En la primera de ellas, reflexionamos sobre el momento que el sistema interestatal atraviesa actualmente y sobre el proceso de reconfiguración hegemónica al que se asiste. En la segunda, analizamos el avance estratégico de China en AL en el siglo XXI observando un rol cada vez más importante del gigante
5. El artículo 24 contenido en el capítulo $\checkmark$ de la Carta Magna de la NN UU referido al Consejo de Seguridad menciona que entre las funciones y poderes de este último se encuentra que "A fin de asegurar acción rápida y eficaz por parte de las NN UU, sus miembros confieren al Consejo de Seguridad la responsabilidad primordial de mantener la paz y la seguridad internacionales, y reconocen que el Consejo de Seguridad actúa a nombre de ellos al desempeñar las funciones que le impone aquella responsabilidad" (Naciones Unidas, 1945). No obstante lo anterior, se observan acciones como la invasión norteamericana a Panamá en 1989; la intervención militar de EE UU y los aliados de la Organización del Tratado del Atlántico del Norte (OTAN) en Kosovo durante el año de 1999; la invasión de EE UU y el Reino Unido a Irak en 2003, entre otras.

6. No es la primera vez que se habla de un posible cambio hegemónico durante la vigencia del sistema interestatal de posguerra. A consecuencia de la crisis global de los años setenta del siglo XX y de manera posterior al fin de la Guerra Fría, existían elementos para pensar que el nuevo liderazgo podía encontrarse en Europa, donde sobresalía Alemania, 0 en Japón. Ambas posibilidades fueron descartadas por el dinamismo que trajo consigo la historia posterior de la economía mundial (ARRIGHI, 1999; ARRIGHI; SILVER, 2001).

7. En el análisis sobre los distintos momentos de crisis hegemónica que ha experimentado la economía mundial, Arrighi y Silver (2001) observan que la aparición de un momento de "caos sistémico" ha formado parte de dichas crisis y de los cambios en los que finalmente han significado colapsos de la hegemonía. Un "caos sistémico" es ocasionado por "la interacción de la intensificación de la competencia interestatal e interempresarial, la escalada de conflictos sociales y el surgimiento intersticial de nuevas configuraciones de poder. Por caos sistémico entendemos una situación de grave y aparentemente irremediable desaorganización sistémica. Cuando la competencia y los conflictos desbordan la capacidad reguladora de las estructuras existentes, surgen intersticialmente nuevas estructuras que desestabilizan aún más la configuración de poder dominante. El desorden tiende a autorreforzarse, amenazando con provocar (o provocando efectivamente) un resquebrajamiento completo de la organización del sistema" (ARRIGHI; SILVER, 2001, p. 40). 
8. La disputa global por los recursos naturales es uno de los elementos más marcados en la dinámica del capitalismo contemporáneo y de su lógica de acumulación. AL es un espacio importante de esta disputa, por la dimensión de las reservas de recursos estratégicos que posee y por su condición histórica de ser una región exportadora de materias primas. El alto grado de vulnerabilidad y dependencia de importaciones que EE UU tiene en relación a un gran número de minerales que AL produce, y la creciente demanda china de estos recursos muestran que la región tiene enormes condiciones de negociación y una oportunidad histórica para asumir soberanamente la gestión económica y científica de los recursos minerales que posee. Por la envergadura de estos objetivos y por la dimensión de los intereses en disputa, éste proyecto solo podrá avanzar si es asumido como una estrategia regional (BRUCKMANN 2012, p. 2)

Sin el desarrollo de un pensamiento estratégico que se afirme en el principio de la soberanía y en una visión de futuro de largo plazo, los países latinoamericanos y la comunidad de países en proceso de integración, tienen menos condiciones de hacer frente a las enormes presiones generadas por esta situación de disputa, donde está en juego, en última instancia, capacidad de re-organización de proyectos hegemónicos y la emergencia de proyectos contra-hegemónicos. Es claro que este conflicto de intereses tiene como telón de fondo visiones societarias y proyectos civilizatorios en choque (BRUCKMANN, 2012, p. 5). asiático en la geopolítica regional. Consideramos la situación de AL como la de un territorio que es disputado ${ }^{8}$ por los principales actores globales, específicamente EE UU y China. Finalmente, en las conclusiones intentamos reflexionar sobre el momento actual y posible rumbo de la región latinoamericana en ese contexto.

Consideraciones sobre la reconfiguración hegemónica mundial desde las relaciones interestatales

No obstante la amplitud de debates en los que se puede insertar este trabajo, dialogamos únicamente con aquellos autores que analizan la conformación de relaciones jerárquicas que asumen los Estados a la hora de suscribir acuerdos dentro del sistema interestatal vigente. Retomamos los argumentos construidos por Leo Panitch y Sam Gindin (2015), Giovanni Arrighi (2007; 2005a; 2005b) y Giovanni Arrighi y Beverly Silver (2001; 2011), en una suerte de discusión sobre el momento actual que vive la economía mundial en general y de las relaciones interestatales en particular.

Desde su postura particular, cada uno de estos autores otorga una interpretación del escenario que en las últimas décadas despliega la economía mundial capitalista: Panitch y Gindin (2015) discuten en torno a la construcción y consolidación del capitalismo global bajo el liderazgo del imperio informal estadounidense que mantiene su poderío; mientras que Arrighi (2007; 2005a; 2005b) y Arrighi y Silver (2001; 2011) plantean la existencia de una situación de caos sistémico que actualmente experimenta la economía mundial, misma que adquiere relevancia para la comprensión del momento en que se encuentra el conjunto de relaciones interestatales.

Leo Panitch y Sam Gindin (2015) plantean que los EE UU son un nuevo tipo de imperio que se distingue de los imperios al estilo clásico cuyo poderío se basó en el dominio político de los territorios y sus poblaciones. Lo que caracteriza a este imperio informal es la manera en que logró articular a una gran cantidad de Estados en torno a un sistema de pagos, bajo la tutela de los EE UU, que rigió a la economía mundial a partir de la segunda posguerra. Este sistema estuvo organizado en torno a propuestas convenientes para la economía norteamericana en la que se considera como la primera de las dos edades de oro que ha vivido el capitalismo estadounidense de 1948 a 1973.

Estos autores sostienen que el imperio informal estadounidense se hizo más fuerte a partir de la década de los setenta ante el colapso de Bretton Woods, momento que para muchos era el inicio del fin de la hegemonía de los EE UU. Este argumento descansa sobre la idea de que, en la medida en que las naciones depositaron su confianza en el dólar y sobre todo en Wall Street para guiar a la economía mundial, se sentaron las bases para la segunda edad de oro del capitalismo estadounidense. La segunda edad de oro va aproximadamente de 1983 al año 2007. Serían los mecanismos generados por un renovado imperio estadounidense los que permitirían la expansión del capitalismo como proyecto global durante este periodo.

El fin de la segunda edad de oro provendría del momento de crisis del 2008 bajo condiciones clave que ahuyentan la posibilidad de que los EE UU vean el fin de su hegemonía. Para Panitch y Gindin (2015) el centro de esta idea está en que dicha nación fue capaz de compartir los 
problemas derivados de la crisis que explotó en el seno de sus instituciones financieras con prácticamente todo el mundo de una forma verdaderamente imperial. Para ellos, la centralidad del Estado estadounidense fue en esos momentos más nítida que en otros momentos, tal y como lo expresan textualmente en las siguientes líneas:

\begin{abstract}
Su decisivo papel en la gestión de la crisis global se confirmó en cuanto la crisis se desplegó, desde el papel de la Reserva Federal, rescatando directamente a bancos extranjeros y proporcionando a otros bancos los muy necesitados dólares, hasta la coordinación del Tesoro de las políticas de estímulo con otros Estados. La enorme demanda de bonos del Tesoro durante la crisis reflejaba el grado en que el Estado estadounidense continuaba siendo considerado el garante final del valor, y demostraba hasta qué punto el mundo seguía instalado en el patrón dólar. Incluso aunque surgieran tensiones internacionales, lo que resultó tan llamativo cuando los dirigentes del G20 se reunieron por primera vez en Washington a finales de 2008 fue el consenso en evitar medidas proteccionistas (PANITCH; GINDIN, 2015, p. 34).
\end{abstract}

A partir del desarrollo de estas ideas, Panitch y Gindin (2015) concluyen que la crisis si bien trajo fisuras, estas no se tradujeron en tensiones entre los Estados capitalistas sino en procesos internos de problemas sociales ${ }^{9}$, que no son concluyentes en cuestionar la hegemonía estadounidense.

Por su parte, Giovanni Arrighi (1999) identifica, a partir de su análisis basado en la existencia de ciclos sistémicos de acumulación, que el periodo posterior a las dos guerras mundiales, en el que también tuvo lugar la gran depresión de los años treinta, es la fase de expansión material del ciclo sistémico de acumulación bajo el liderazgo de los EE UU. Desde esa perspectiva, Arrighi (1999) identifica a la crisis sistémica de la década de los setenta como la crisis señal del ciclo sistémico estadounidense que da paso a la fase de expansión financiera del mismo.

Con la crisis del 2008 EE UU sufre una disociación entre su poder militar y su poder económico-financiero, pues actualmente el primero lo ejerce mientras que el segundo está en China. Se observa claramente cómo la primera ha pasado de ser una nación líder acreedora a la mayor deudora mundial de una manera sumamente veloz.

Para Arrighi (2007; 2005a; 2005b) la economía mundial se encuentra en un periodo de caos sistémico. Esta idea puede asociarse al actual periodo de crisis mundial caracterizado por la incertidumbre respecto al declive de la hegemonía estadounidense y a las posibles configuraciones futuras de la economía-mundo capitalista y del sistema inter-estatal.

\begin{abstract}
Las corporaciones multinacionales de Estados Unidos de América han estado invirtiendo fuertemente en China, repitiendo el patrón histórico observado por Marx en el cual los centros en declive transfieren superávits de capital a los centros en ascenso. Sin embargo, en una salida importante de los patrones del pasado, el flujo neto de superávit de capital, desde el comienzo de la expansión financiera liderada por Estados Unidos, ha estado notablemente en la forma de compras masivas desde Asia Oriental de Bonos del Tesoro de Estados Unidos, primero por Japón, luego por China (ARRIGHI; SILVER, 2011, p. 63).
\end{abstract}

Arrighi pone el acento en dos fenómenos, por un lado, el ascenso y declive del "Proyecto para un Nuevo Siglo Americano" diseñado por los neoconservadores estadunidenses y, por el otro, el surgimiento de China como adalid del resurgimiento económico de Asia oriental (2007, p. 5). Esto llevaría al gigante asiático al centro de la economía política global, donde jugaría un papel importante la nueva estrategia de striving for achievement ${ }^{10}$,
9. Costas Lapavistas (2016) cuestiona de manera tangencial la propuesta de Panitch y Gindin, sin que el centro de su análisis sea el de identificar el rol hegemónico de EE UU en la economía mundial. De manera específica critica la idea de que "la financiarización es la 'americanización' de las finanzas que ha servido para fortalecer y universalizar el poder de EE UU" gracias al papel que el dólar posee en este proceso y la dificultad de que esta moneda encuentre un rival que pueda sustituirlo. Por lo que es discutible que la posición hegemónica de los EE UU se haya fortalecido (LAPAVISTAS, 2016, p. 52).

10. En el marco de la conferencia de asuntos exteriores del Partido Comunista Chino (PCCh) el 24 de octubre de 2013, el presidente chino Xi Jinping pronunció un discurso en el que presentó formalmente la estrategia de striving for achievement (fenfayouwei) o "lucha por el logro", señalando una transformación de la vieja estrategia de kepping a low profile o "mantener un perfil bajo". La diferencia clave entre ambos es que el primero se centra en las ganancias económicas y el segundo busca fortalecer el apoyo político y valora más el papel de la moralidad, lo cual ha logrado incluso un progreso más allá de las expectativas personales del presidente Xi al crear un ambiente internacional más favorable para China (XUETONG, 2014, p. 153-154). 
11. Con la One Belt One Road Initiative (OBOR), lanzada por Xi Jinping en 2013 y oficializada en 2015 , China pretende integrar verticalmente la Ruta terrestre de la Seda de Eurasia con la nueva Ruta marítima de la Seda que conecta el Mar de China con el Océano Índico, el Golfo Pérsico, el Mar de Arabia y el Mediterráneo con sendos brazos hacia el Pacífico por Oriente y las regiones costeras con el Î́ndico de África. El alcance transcontinental de la OBOR muestra que China, en esta segunda oleada de su desarrollo hacia el exterior, pretende influir de manera decisiva en la distribución del poder mundial (DOMÍNGUEZ, 2018b, p. 163-164).

12. China jugará un papel muy importante en el futuro de la integración latinoamericana, pues por ejemplo tiene la posibilidad de articularse con los países de la Alianza del Pacífico (AP), que, a pesar de responder a los intereses del Consenso de Washington, perdieron momentáneamente su rumbo tras la decisión de Donald Trump de abandonar el Acuerdo Transpacífico de Cooperación Económica en enero de 2018. Por su parte, la Comunidad de

Estados Latinoamericanos y Caribeños

(CELAC) sigue siendo el canal de comunicación preferido por el Gobierno chino que ha intentado con éxito implementar un modelo de CSS ampliada, es decir incluyendo comercio e inversión bosquejado a partir del Documento de I Foro China-CELAC y el Policy Paper de China para AL de 2016, así como el plan de acción presentado en el II Foro China-CELAC de 2018 para profundizar la cooperación económica, la solidaridad y la complementariedad en beneficio mutuo. No obstante, la inclinación a la derecha en la balanza política de

$A L$ en años recientes ha paralizado los proyectos de integración regional desarrollados en la década previa. Tal es el caso de la Unión de Naciones Suramericanas (UNASUR) convertida en un "elefante banco" después de que en 2018 fuera abandonada por siete de sus doce miembros. Es importante señalar, que ante el actual panorama político regional, tal como señala Gordon Mace

(2018), la eventual desaparición de la UNASUR significaría la pérdida de un foro diplomático necesario, al tiempo que daría testimonio de una profunda crisis del regionalismo sudamericano

Finalmente, en cuanto a la Alianza Bolivariana de Nuestra América-Tratado de Comercio de los Pueblos (ALBA-TCP) se encuentra en el ocaso tras la crisis de Venezuela, que era el principal país impulsor de esta iniciativa. lanzada por Xi Jinping en mayo de 2013 en la Conferencia de Trabajo sobre la Diplomacia Periférica (XUETONG, 2014; 2016).

Entre 2016 y el comienzo de 2017, la economía mundial capitalista ha vivido momentos que han puesto en discusión el actual modelo de globalización neoliberal. Por un lado, la presidencia de Donald Trump en EE UU muestra un escenario cada vez más complejo que podría reconfigurar el actual modelo de relaciones económicas y políticas globales. Para el territorio latinoamericano esto significaría un desafío en el objetivo de lograr mayor autonomía en su inserción en la economía global. Por otro lado, el proyecto de la "One Belt, One Road" (OBOR) $)^{11}$ lanzado por China, podría ser la base para la construcción de un nuevo sistema interestatal con el liderazgo de Beijing bajo la propuesta de la Nueva Economía Estructural (NEE) (LIN; WANG, 2017, p. 15-16).

La discusión anterior, nos permite introducir el panorama que a nivel de la economía mundial existe en torno a los procesos de reconfiguración hegemónica y la manera en que la región latinoamericana se encuentra inserta en dicho contexto. En este sentido, el impulso hacia una transición hegemónica asume hoy un significado importante en el cual el papel de los países emergentes es fundamental en el entendimiento de este proceso en el que sin duda China adquiere un rol fundamental.

Las contradicciones que vive hoy el capitalismo global ponen de manifiesto que $\mathrm{AL}$ adquiere el rasgo de ser cada vez más un territorio en disputa entre los actores que buscan convertirse o mantenerse como hegemonía global en la actualidad. Nos parece importante señalar que AL es y ha sido, en las últimas dos décadas, una región que se encuentra en una constante reconfiguración que no se aparta de los procesos de un mundo globalizado. Efectivamente, a partir del siglo XXI los gobiernos latinoamericanos han intentado tomar las riendas de su propio destino constituyendo diversos procesos formales de integración ${ }^{12}$. Por ello, se ha puesto en juego el papel de cada país latinoamericano en el ajedrez de este sistema interestatal para consolidar distintos modelos de integración ${ }^{13}$ que les ha permitido en cierto modo tomar liderazgo regional. Este escenario, se reorganiza a partir de un mayor acercamiento de China en AL y, al mismo tiempo, del debilitamiento de las relaciones entre EE UU y varios países latinoamericanos. Sin embargo, también podría considerarse lo que Gallagher (2016) denomina China Triangle, una estructura donde los vértices son China y EE UU con los que AL fomentaría relaciones políticas y comerciales interactuando simultáneamente con ambos actores y sin tener que escoger entre uno u otro.

\section{El avance estratégico de China en América Latina en el siglo XXI}

Mirar a Latinoamérica como región, es reafirmar su posición en un mundo globalizado, dentro de un marco capitalista en el cual los mercados de carácter global enfatizan las relaciones políticas y económicas internacionales. Aunque las alternativas de cambio y desarrollo social en AL se han dado en un contexto pragmático y real que no va más allá del capitalismo, los países latinoamericanos han podido avanzar hacia nuevos objetivos y estrategias basados en el diálogo político, los acuerdos 
comerciales y la búsqueda de una nueva forma de financiamiento. Ante tal escenario, tal como señala Domínguez (2018a, p. 60), China está a punto de terminar el diseño de un nuevo régimen de Cooperación Sur-Sur (CSS) como parte de los andamiajes del potencial sistema interestatal que fomenta. Esto impliacaría un liderazgo chino a través del gran salto realizado por este país en términos de potencia y credibilidad estratégica internacional, o, dicho de otro modo, gracias a su irresistible resurgimiento (frente a la imparable pérdida de peso económico y autoridad política de EE UU). Y, AL acapararía en este momento algunas sinergias que la iniciativa china OBOR está impulsando.

La cooperación integral entre China y AL ayudaría a aumentar su fuerza y su capacidad de desarrollo teniendo como telón de fondo el profundo ajuste actual del sistema mundial en un momento de poscrisis financiera internacional (HAIBIN, 2018, p. 219).

En este sentido, pensar en una posición de AL, es hablar sobre regionalismo y multilateralismo, y el papel que estas visiones tienen para desarrollarse como actores en el marco de la economía mundial capitalista. Partir desde esta posición nos remite a la idea que "las regiones son socialmente construidas y, por lo tanto, pueden ser políticamente disputadas" (HURREL, 1995, p. 38). Este pensamiento reafirma la posición de AL como una región construida y también abre el panorama para referirse a ella como un territorio en constante disputa.

La zona se ha construido en gran medida por los intereses y la influencia de terceros, como distintas potencias europeas, pero sobre todo por los EE UU, aunque hoy en día China se presente como otro actor que busca influenciar los procesos latinoamericanos a través de la estrategia del softbalancing ${ }^{14}$ y sin enfrentar directamente a su contraparte. Por el contrario, parece ser que los proyectos latinoamericanos por importantes y autonómicos que suponen haber sido se inscriben en una estrategia global en la que EE UU y China han aprovechado, y en el que su lugar de periferia de la economía mundial capitalista no ha sido puesta en discusión, no obstante los renovados procesos democráticos y de cambio en un marco neoextractivista.

Estas características convierten a la región en un territorio en disputa que se enfrenta a una fragmentación interna entre los diversos Estados que la conforman, al tiempo que se presenta como un espacio cada vez menos sólido en el exterior, con menor capacidad de negociación internacional con otros actores como EE UU, la Unión Europea o China que tienen claros intereses geoestratégicos en la zona.

El ascenso de China en la geopolítica mundial es el resultado de una estrategia de más de cuarenta años que, con los relativos matices que la han caracterizado, revela la voluntad de impulsar un cambio en el actual sistema interestatal. En ese sentido, las relaciones entre China y AL están enmarcadas: a) en la estrategia global del dragón asiático conocida como la OBOR b) en el documento político conocido como "Libro Blanco" sobre América Latina y el Caribe en 2008, que define la estructura de los objetivos chinos en la región en el contexto de esta globalización proponiéndose fomentar un comercio equilibrado y el estímulo de inversiones y cooperación en distintos ámbitos bajo los ejes de la política exterior china ${ }^{15}$; c) en
13. La integración es una concepción estricta y se concibe como un proceso gradual de acercamiento multidimensional e interdependencia económica entre países con proyectos nacionales compatibles de desarrollo, para alcanzar objetivos comunes, en condiciones de ventajas mutuas, mediante la concertación y la convergencia paulatina, sobre base de principios solidarios de cooperación (ÁLVAREZ, 2012, p. 180).

14. El concepto de softbalancing 0 "equilibrio suave" parte de la idea que las instituciones internacionales son secundarias para la distribución del poder en el sistema internacional y por ello no pueden crear serios desafíos a dicha distribución. Por lo tanto, este concepto se discute como un método para superar los problemas de coordinación bajo la anarquía del sistema internacional, recurriendo a la tesis institucionalistas en las que los Estados secundarios pueden usar las instituciones para abordar diversas necesidades: a veces pueden facilitar la coordinación con un poder unipolar o en oposición a él, o bien, como foros para publicitar y deslegitimar el unilateralismo unipolar. (FRIEDMAN; LONG, 2015, p. 130)

15. Respeto mutuo por la soberanía y la integridad territorial, la no agresión mutua, la no interferencia en los asuntos internos de otros países, igualdad y beneficio mutuo, y la coexistencia pacífica. Estos principios reflejan plenamente los propósitos y principios de la Carta de la ONU y constituyen la base jurídica para la conformación del nuevo orden internacional. 
16. Están basados en los principios de beneficios mutuos, igualdad y desarrollo.

17. El discurso del Consejero de Estado chino Dai Bingguo que pronunció en nombre del Presidente Hu Jintao en el diálogo del G8 más países en desarrollo en China, en julio de 2009, es considerado como la primera declaración oficial de China sobre la gobernanza mundia destacando la necesidad de promover el desarrollo coordinado y sostenible de la economía mundial incluyendo elementos como la representación equilibrada y beneficios mutuos como resultados de un juego de ganar-ganar (win-win), que significa combinar los intereses y vincula el desarrollo de un país con los demás (PANG; LYE, 2012, p. 528-529). Luego, en su discurso en el Foro Boap sobre la "Comunidad del Destino Común" de Asia en 2015, el presidente Xi Jinping, explicó la concepción de China de las relaciones de "ganar-ganar" en Asia y el mundo, Io cual es considerado el centro del enfoque de la política exterior de China al articular

cuestiones económicas como el Asian Infrastructure Investment Bank (AIIB) y la OBOR para los enlaces de infraestructura en el continente asiático con observaciones más amplias sobre las relaciones culturales y de "civilización" entre los países

involucrados (CHINA.ORG.CN, 2018)

18. La OBOR se enfocará a reforzar las relaciones con sus vecinos geográficos inmediatos, desplazando algunas de las sinergias hasta ahora enfocadas en la región latinoamericana. Representa un mercado de mayores alcances para el país asiático, y a la vez ofrecerá un espacio económico ideal para la repro ducción del capital real y especulativo.

19. El desarrollo inclusivo es un requisito inevitable para materializar la vocación de China por una sociedad armoniosa y un mundo armonioso. En este sentido la idea de un "desarrollo armonioso" parte de la insistencia del gobierno chino en la salvaguardia y la mejora del bienestar social como punto de partida y destino de todas sus actuaciones, fijando como prioridad profundizar la reforma al sistema de distribución de ingreso, con el objetivo de resolver desde la raíz el problema del desequilibrio en la distribución de la riqueza social. De esta forma se afirma un sistema de protección social, caracterizado por la equidad en derechos, oportunidades y reglas de juego, para asegurar que el fruto de desarrollo beneficie en mayor medida y de manera más equitativa a toda la población (EMBAJADA DE LA RPCH EN LA REPÚBLICA DE CHILE, 2013) los 5 principios de coexistencia pacífica ${ }^{16}$; d) en el reconocimiento de una sola China; e) en el Foro China-CELAC de 2015 y su Plan de Cooperación 2015-2019, que se ha vuelto a significar como "cooperación económica" (DOMÍNGUEZ, 2016); f) en el segundo "Libro Blanco" sobre América Latina publicado en 2016; y, finalmente, g) en el principio win-win ${ }^{17}$. En ese sentido, la región latinoamericana viene considerada como un espacio importante del mundo en desarrollo y estratégica en la arena del nuevo ajedrez de poder a nivel global (THE STATE COUNCIL OF PEOPLE'S REPUBLIC OF CHINA, 2016).

Aunque AL no sería el principal espacio económico y político de la nueva estrategia china del siglo XXI la OBOR ${ }^{18 ”}$, los países de AL ofrecen una serie de oportunidades para mejorar el clima general para el "desarrollo armonioso ${ }^{19}$ " del gigante asiático en el escenario mundial (PICCONE, 2016, p. 1) marcando como objetivos estratégicos en la región el respeto mutuo, la profundización de la cooperación y la intensificación de los intercambios económicos-comerciales. Esto se contrasta con la relación de subordinación que AL ha tenido hacia los intereses de los EE UU bajo el régimen de posguerra.

En este sentido, China se presenta como un actor con reglas distintas en su cooperación con AL. Su sistema de valores a la hora de establecer relaciones económicas y políticas con otros países, especialmente con los de la región latinoamericana, tiende a ser interpretado por estos como generador de beneficios para todos. Esto difiere, cada vez más, con la dinámica que han adquirido las relaciones de algunas naciones latinoamericanas con los EE UU, aunque otras le apuestan a que todavía la visión de ese Estado es la mejor opción a seguir. Estos elementos pueden pensarse desde la idea de caos sistémico de Arrighi y Silver (2001), pues existe más de una nación cuyos intereses promueven valores particulares que dificultan la posibilidad de ver con claridad la existencia de un orden hegemónico. Se observa un momento en el que existen nuevos referentes con la potencialidad de asumir un liderazgo a partir de que sus objetivos tienden a presentarse como el interés general, condicionando así las dinámicas de relaciones interestatales.

Para argumentar nuestra hipótesis de cómo el ascenso chino podría representar el comienzo de un nuevo sistema interestatal que aún no termina de conformarse ante otro que no acaba de colapsar, nos parece importante recuperar la idea de Giovanni Arrighi según la cual:

\footnotetext{
La mayoría de las características del regreso de China a una economía de mercado son más acordes con esa concepción del desarrollo basado en el mercado que con la concepción marxiana del desarrollo capitalista, según la cual el gobierno desempeña el papel de comité que gestiona los asuntos comunes de la burguesía y como tal facilita la separación entre los productores directos y los medios de producción así como la tendencia de los acumuladores capitalistas a descargar las presiones competitivas sobre los trabajadores (ARRIGHI, 2007, p. 372).
}

Lo que queremos resaltar de este argumento es que, siguiendo la idea de Arrighi (2007), no obstante China haya buscado la ayuda de los capitalistas extranjeros en la consolidación de su papel en las dinámicas de la economía mundial, ha mantenido la capacidad de dirigir estas acciones siendo hoy el principal acreedor de los EE UU. Además, el no haber 
adoptado totalmente los dictámenes del Consenso de Washington le ha permitido sortear las dinámicas neoliberales y, de esa manera, impulsar su propio modelo de globalización a partir de su entrada en la Organización Mundial del Comercio (OMC) en el 2001. La combinación de estos elementos con el impulso a la iniciativa de la "OBOR", ha fomentado la implementación de un nuevo sistema de comercio multilateral basado en la voluntad de reformar la gobernanza global para, tal como señala Domínguez, edificar un sistema económico abierto (2016, p. 59-60).

A comienzos de la segunda década del presente siglo, China vivió una desaceleración en su ritmo de crecimiento económico como consecuencia del periodo depresivo que atravesó la economía mundial a partir de la crisis inmobiliaria del 2008 que se originó Pen los EE UU. Como consecuencia, en el año 2009, el gigante asiático formuló una estrategia de política externa que prioriza las relaciones con el sur global promoviendo asociaciones estratégicas, vínculos económicos y alianzas al interior de los organismos internacionales (VADELL, 2018). Esta política, que mantiene relación con el mundo desarrollado y la profundiza con el sur global, encuentra su más clara expresión en la mencionada iniciativa OBOR.

China está en condiciones de situarse, a partir de esta estrategia como el nuevo líder de un régimen de CSS y por tal motivo, es importante señalar que esta iniciativa abarca también (por la "Ruta Marítima de la Seda") a $\mathrm{AL}^{20}$, con algunos de los macro proyectos financiados con capital chino como la plataforma de la isla de Cuba a modo de base naval y los proyectos de comunicación del Gran Canal de Nicaragua ${ }^{21}$, el ferrocarril bioceánico Brasil-Perú y el túnel Argentina-Chile (DOMINGUEZ, 2018a, p. 56).

La iniciativa OBOR frente a veintinueve jefes de estados y de gobierno celebrada en Pekín en mayo de 2017, puede ser considerada como una nueva forma de impulsar el desarrollo, con el objetivo de ampliar los vínculos entre Asia, África, Europa y América, acompañada de inversiones en infraestructura por miles de millones de dólares. Un proyecto sin duda que fortalece aún más el liderazgo chino en la economía mundial y que abre nuevos escenarios en lo que muchos definen el proyecto de globalización 2.0.

El Banco Asiático de Inversión en Infraestructura (AIIB), el Nuevo Banco de Desarrollo (NDB) en el marco de los BRICS ${ }^{22}$, la Agencia Estatal de Cooperación Internacional para el Desarrollo de China creada apenas en abril de 2018, y el Fondo de la Nueva Ruta de la Seda, marcarían el camino hacia ese nuevo sistema interestatal. En palabras de Stuenkel (2016) este representaría la base de un mundo posoccidental. Señalamos también que China liderará pronto el nuevo régimen de CSS gracias al gran salto realizado por este país en términos de potencia y credibilidad estratégica internacional que será alternativo al del Comité de Ayuda al Desarrollo (CAD). En éste último, la institucionalidad en el plano financiero, el development compact ${ }^{23}$ y la financiarización amplia del desarrollo, y, el sistema de monitoreo y evaluación serán los tres pilares con los que el gigante asiático se afianzará a nivel global como el líder y arquitecto de este nuevo régimen (DOMÍNGUEZ, 2018a, p.60-62). Además, la nueva
20. La OBOR abarca también por la Ruta Marítima a AL, comprendiendo por el momento cuatro megaproyectos. (i) a modo de base naval, desde 2011 se instaló en Cuba una plataforma de perforación petrolera construida en China con la alta tecnología Scarabeo 9, de

Saipem, propiedad de la petrolera italiana Eni SpA y contratada por la española Repsol YPF, que es capaz de perforar un máximo de 12000 pies (3 600 metros) en aguas profundas (LA JORNADA, 2010). Asimismo, en proyectos de comunicación se prevé (ii) la construcción del Gran Canal de Nicaragua que ya inició en 2014, previendo su conclusión en 2019, con un proyecto valorado en \$USD 50.000 millones a cargo de la empresa HKND, propiedad del multimillonario chino Wang Jing, con sede en Hong Kong, que recibió una concesión de 50 años por los derechos de construir el canal y otros

50 años para manejarlo (BBC, 2014); también se encuentra (iii) el ferrocarril bioceánico Brasil-Perú cuya viabilidad ha sido confirmada y se espera una financiación de \$USD 14.000 millones estimados para la obra que debe estar totalmente concluida en 2024, mediante una asociación entre capitales públicos y privados (NAVARRO, 2018); por último (iv) el túnel Argentina-Chile que pasará por debajo de la Cordillera de los Andes, a los largo de 13,9 kilómetros, con un costo de \$USD 1.500 millones y que ya tuvo su puntapié inicial en 2017 al dar a conocer las 29 empresas que precalificaron para participar en el proyecto que concluirá cerca del 2027, destacando entre ellas ACS, China Railway (CR), Skanska, Vinci Construction y Bechtel Corporation (EL PAÍS, 2018).

21. El proyecto del Canal Interoceánico de Nicaragua parecía ser la obra cumbre del mandato de Daniel Ortega al dar un giro al comercio marítimo mundial compitiendo con el Canal de Panamá. Sin embargo, lejos de convertirse en una realidad, el megaproyecto se ha vuelto cada vez más inviable por los enfrentamientos entre el gobierno y los sectores opositores del país, además de que en los últimos meses no ha recibido el debido apoyo del empresario chino Wang Jing, quien lidera a la firma HKND encargada del proyecto (PANTALEÓN, 2018). Además, este proyecto presenta muchos interrogantes debido a la paralización de la obra, la fragmentación de la fuente, y las diversas opiniones en cuanto a la construcción del mismo (FERNÁNDEZ; ROMERO, 2018, p. 94).

22. Brasil, Rusia, India, China y Sudáfrica.

23. Señala Domínguez (2018a, p. 62) que es el concepto que da coherencia a la cooperación de India, y que ha ganado rápidamente aceptación en NN UU como nueva métrica. 
24. En la ciudad de Davos, Suiza, entre los días 17 y 20 de enero de 2017, se celebró el Word Economic Forum reuniendo a políticos, empresarios y economistas de todo el mundo para tratar las temáticas referentes a la incertidumbre económica global y a las transformaciones sociales.

25. Nos referimos a la crisis de la economía mundial que golpeó a los países desarrollados.

26. Nos referimos a la crisis de la economía mundial que golpeó a los países en desarrollo.

27. La acelerada globalización capitalista suponía grandes cambios en todas partes comprobables sobre todo en: a) la masiva expansión de las finanzas en la acumulación global; b) en el impacto de las redes de producción integradas dentro de la división global del trabajo; y c) en los novedosos aspectos de la centralidad económica de EE UU en el capitalismo global (PANITCH: GINDIN, 2015, p. 418). Para estos dos autores estos cambios verían a EE UU consolidarse como el "Estado imperial" en la construcción del capitalismo global.

28. Con este término nos referimos al nuevo modelo de globalización que está impulsando China a partir de la perspectiva de la Nueva Economía Estructural teorizada por Justin Yifu Lin (2012).

29. Entre 2005 y 2016 Venezuela, Brasil, Ecuador, Argentina y Bolivia han sido los países que han recibido la mayor cantidad de créditos resaltando el sector energético y el de infraestructura.

30. Entre el 2005 y el 2016 el país que más Inversión Directa Extranjera (IED) ha recibido es Brasil con un monto de 61,000 millones de dólares, seguido por Perú por 18,000 millones de dólares. En cuanto, a los sectores en el que se centran dichas inversiones resaltan el Gas y Petróleo (25 000 millones de dólares), la minería y los metales (27,000 millones de dólares) y Ilama la atención el crecimiento del sector servicios (7,000 millones de dólares).

31. Desde el 2000 se han firmado 11 acuerdos de asociación estratégica (Venezuela en 2001; México en 2003 y 2013; Argentina en 2001 y 2004; Perú en 2004, 2008 y 2013; Chile en 2004 y 2012;

Ecuador en 2016); 3 Tratados de Libre Comercio (TLCs), (Costa Rica en 2005; Perú en 2009 y Chile en 2015.); se han creado

35 institutos confucios en 20 países; se han establecido varios acuerdos de intercambio de divisas con Argentina, Brasil y

Chile; China se ha convertido en accionista del Banco Interamericano del Desarrollo (BID) en 2009 y observador en la Organización de los Estados Americanos (OEA) en 2004 y en la Comisión Económica para América Latina (CEPAL) en el mismo año. estrategia de striving for achievement de China respondería a ese momento de transición hegemónica.

Consideramos que en Davos $2017^{24}$ ha sido novedoso el discurso del presidente Xi acerca del papel que puede jugar una globalización que otorgue beneficios para todos. Esto, frente a lo que parece delinearse como proyecto nacionalista privatizador del presidente norteamericano Donald Trump que arremete contra no solamente esta globalización neoliberal, sino ante cualquier tipo de reglas económicas y comerciales que no vean las ventajas de los EE UU por encima de los demás. Al mismo tiempo, mencionamos que el modelo Trump responde a la desesperada estrategia de revivir el "Nuevo Siglo Conservador Americano" inaugurado por George W. Bush en 2001 que intentó, a comienzo de este nuevo milenio, impulsar la hegemonía estadounidense frente a la avanzada china, estimulando de esta forma una nueva manera del desarrollo basado en la securitización (con un enorme gasto en el sector militar).

Sin embargo, las distintas crisis del $2008^{25}$ y del $2014^{26}$ darían un duro golpe al papel del "Estado imperial" estadounidense cuestionando la hipótesis ${ }^{27}$ de Leo Panitch y Sam Gindin de que la crisis del 2008 y su intento de solución por parte de los EE UU reforzaría el lugar de este país en el capitalismo global. Dado que, como señalan estos autores, EE UU "es el epicentro de la crisis financiera global, pero el dólar estadounidense sigue siendo el refugio seguro" (PANITCH; GINDIN, 2015, p. 481).

En este sentido, la nueva globalización Sur-Sur ${ }^{28}$ impulsada por China posee elementos para el surgimiento de un nuevo sistema interestatal paralelo aunque dudosamente sustituto del actual. A tal propósito, en relación a la región latinoamericana, señalamos los enormes créditos $^{29}$, préstamos e inver$\operatorname{siones}^{30}$ acompañados por numerosos acuerdos estratégicos y tratados de libre comercio $^{31}$ que el gigante asiático ha materializado en este nuevo milenio con los distintos países latinoamericanos. No obstante, hay que hacer hincapié en que la disminución en el financiamiento de China hacia AL en el 2017 se debe a que los fondos regionales han adquirido mayor relevancia en los últimos años, pero podría volver a aumentar si se aprobarán proyectos integrados a la iniciativa china de la OBOR en la región (MYERS; GALLAGHER, 2018).

Reflexiones finales

Para Panitch y Gindin (2015, p. 405):

En el nuevo milenio se producía un claro proceso de desarrollo capitalista en el sur global, aunque todavía fuera sumamente desigual y el éxito estadounidense en crear un mundo a su imagen y semejanza se comprobaba por todo el mundo en el funcionamiento de las empresas en un entorno en el que el modelo estadounidense de capitalismo se consideraba evidentemente correcto en sí mismo.

Sin embargo, el siglo XXI vislumbró un cambio en la forma de acumulación global en que las grandes Empresas Transnacionales (ET), que organizan la producción de mercancías a escala planetaria, encontraron conveniente la migración de numerosos procesos fabriles hacia la región de Asia-Pacífico (SLIPAK, 2014). En este sentido, tal como señala Stuenkel (2016), vivimos el reflejo de un mundo cada vez más centrado en Asia, como resultado de un cambio histórico del poder de Occidente hacia el continente que concentra más de la mitad de la población mundial. 
Este trabajo argumenta lo que prefigurábamos en al inicio del artículo, es decir, que el actual momento de crisis de la economía mundial muestra el debilitamiento de los acuerdos suscritos en la Carta de las Naciones Unidas en 1945 y que, tal como se ha intentado señalar, vivimos el surgimiento de un nuevo orden interestatal que coexiste con éste último pero que poco a poco va ganando terreno con China como líder.

En cuanto a AL, esta situación marcaría también el aspecto político en la región dado que a partir del nuevo escenario electoral que se ha desarrollado en México ${ }^{32}$ y en Brasil ${ }^{33}$, se podrían construir distintos proyectos de integración que mirarían ya sea hacia China o hacia EE UU. En este sentido, se evidencia que las relaciones entre estados van adquiriendo rasgos de un sistema interestatal centrado en Asia que coexiste con el de la segunda posguerra.

Finalmente, el nuevo entramado de instituciones que China ha ido creando a lo largo de estos últimos años daría paso a un "multilateralismo competitivo" (STUENKEL, 2017, p. 240) que, más que generar rupturas con el actual sistema interestatal, los haría convivir permitiendo nuevas prácticas y dinámicas de interacción global.

Bibliografía

ARRIGHI, G. Adam Smith en Pekin: orígenes y fundamentos del siglo XXI. Madrid: Akal, 2007.

ARRIGHI, G. Comprender la hegemonía-1. New Left Review, v. 32, p. 20-74, 2005 a.

ARRIGHI, G. Comprender la hegemonía-2. New Left Review, v. 33, p. 24-54, 2005 b.

ARRIGHI, G. El largo siglo XX. Madrid: Akal, 1999.

ARRIGHI, G.; SILVER, Bevely. Caos y orden en el sistema-mundo moderno. Madrid: Akal, 2001.

ARRIGHI, G; SILVER, B. The End of the Long Twentieth Century. In: CALHOUN, C.; DERLUGUIAN, G. (eds.), Business as Usual: the Roots of the Global Financial Meltdown. New York: New York University Press, 2011. cap. 1, p, 53-68.

ÁLVAREZ, O. La CELAC nuevo actor regional en América Latina y el Caribe. Avales y obstáculos para lograr su consolidación. Anuario de la Integración Regional de América Latina y el Gran Caribe 2012. 2012. Disponible en: http://www.cries.org/?p=1328. Acceso el 25 jun. 2018.

BBC, Los impresionantes números del Gran canal de Nicaragua. BBC Mundo, 22 dic. 2017. Disponible en: https://www.bbc.com/mundo/noticias/2014/07/140708_economia_canal_nicaragua_cifras_nc. Acceso 27 sep. 2018.

BRUCKMANN, M. Recursos naturales y la geopolítica de la integración sudamericana, Perú: Perumundo-Fondo Editorial Carlos Mariátegui, 2012.

CHINA.ORG.CN. Full text of Chinese President's speech at Boao Forum for Asia. China.org.cn, 29 mar. 2015. Disponible en: http://www.china.org.cn/business/2015-03/29/content_35185720. htm. Acceso el 27 sep. 2018.

DOMINGUÉZ, R. China y la construcción de un régimen internacional de Cooperación SurSur. Carta Internacional, v. 13, n. 1, p. 38-72, 2018a.

DOMÍNGUEZ, R. China y el renacimiento de África. In: VADELL, J. (org.) A expansão econômica e geopolítica da China no século XXI: diferentes dimensões de um mesmo proceso. Belo Horizonte: Editorial PUC Minas, 2018b.

DOMÍNGUEZ, R. En los pliegues de la historia: Cooperación Sur-Sur y procesos de integración en América Latina y el Caribe. Estudos Internacionais, v. 4, n.2, p. 57-77, 2016.

EL PAÍS. Así será el túnel que unirá Argentina y Chile por debajo de la Cordillera. El País, 31 may. 2017. Disponible en: https://www.elpais.com.uy/mundo/asi-sera-tunel-unira-argentina-chile-debajo-cordillera.html. Acceso el 27 sep. 2018.

EMBAJADA DE LA REPÚBLICA POPULAR DE CHINA EN LA REPÚBLICA DE CHILE. El desarrollo de China entra en una nueva etapa. 2013, Cl.chinaembassy.org. Disponible en: http:// cl.china-embassy.org/esp/dsjh/t1022979.htm. Acceso el 25 sep. 2018.
32. Andrés Manuel López Obrador lider de Morena resultó ganador en las elecciones del primero de julio de 2018, marcando la historia de México, donde por primera vez un presidente de izquierda gobernará a uno de los países más importantes y estratégicos de AL.

33. Jair Messias Bolsonaro, líder de Partido Social Liberal (PSL) ganó en la segunda vuelta las elecciones a la presidencia de Brasil el pasado 29 de octubre, marcando un giro a la derecha extrema en el país carioca que podría cambiar su papel en los esquemas de integración y cooperación regional y global. 
FERNÁNDEZ, P. D., ROMERO, F. G. El proyecto del canal interoceánico en Nicaragua y la incidencia de capitales chinos en América Central. Revista Coyuntura Austral, v.9, n. 46; abr.jun. p. 83-99, 2018,

FRIEDMAN, M. P.; LONG, T. Soft Balancing in the Americas, Latin American Opposition to U.S. Intervention, 1898-1936. International Security, v., n. 40, p. 120-156, 2015.

GALLAGHER, K. The China Triangle. Latin American's Cina Boom ande the Fate of Washington Consensus. New York: Oxford University Press, 2016.

HAIBIN, N. La mejora de la cooperación general con América Latina y el Caribe. In: BAIYI, W. (ed.), Pensamiento social chino sobre América Latina. Buenos Aires: CLACSO. cap. 9, p. 217-237.

HURRELL, A. Regionalism in Theoretical Perspective. In: FAWCETT, L.; HURRELL, A. (ed.) Regionalism in World Politics: Regional Organization and International Order. Oxford: Oxford University Press. 1995. Cap. 3, p. 37-73.

LA JORNADA. Llegará a Cuba una plataforma china de perforación el año próximo. La Jornada, 1 ago. 2010. Disponible en: http://www.jornada.com.mx/2010/08/01/index.php?section=economia\&article=022n2eco. Acceso el 27 sep. 2018.

LAPAVISTAS, C. Beneficios sin producción, Como nos explotan las finanzas. Madrid: Traficantes de sueños, 2016.

LIN, J. Y. New Structural Economics, A Framework for Rethinking Development and Policy. Washington D.C.: World Bank, 2012.

LIN, J. Y.; WANG, Y. Going Beyond Aid, Development, Cooperation for Structural Transformation, United Kingdom: Cambridge Press University. 2017.

MACE, G. Fracture de l'UNASUR? Crise du régionalisme sud-américain?, Centre d'études interaméricaines, Collectio Documents de politiques, n. 2018-1, 2018.

MYERS, M.; y GALLAGHER, K. Chinese development finance "down but not out" in Latin America. The Global Americans, mar. 2018. Disponible en: https://theglobalamericans. org/2018/03/chinese-development-finance-not-latin-america/. Acceso el 30 mar. 2018.

NACIONES UNIDAS, Carta de las Naciones Unidas, un.org, 1945. Disponible en: http://www. un.org/es/charter-united-nations/index.html. Acceso el 27 mar. 2018.

NAVARRO, E. J. ¿Una solución?: Firman el reglamento del tren bioceánico que cruzará cuatro naciones de Suramérica. RT noticias, 21 jun. 2018. Disponible en: https://actualidad.rt. com/actualidad/277262-tren-bioceanico-cruzara-cuatro-naciones. Acceso el 27 sep. 2018.

PANITCH, L.; GINDIN, S. La construcción del capitalismo global. La economía política del imperio estadounidense. Madrid: Akal, 2015.

PANG, Z.; LYE, L. F. China and Global Governance. In: WANG, G.; ZHENG, Y. (eds.), China Development and Governance. Singapore: Singapore World Scientific, 2012. cap. 57, p. 527-532.

PANTALEÓN, I. Canal de Nicaragua: una megaobra que se desvanece. Forbes México, 2018. Disponible en: https://www.forbes.com.mx/canal-de-nicaragua-una-megaobra-que-se-desvanece/, 2018, Acceso el 25 sep. 2018.

PICCONE, T. The Geopolitics of China's Rise in Latin America, Washington D.C., The Broookings Institution, 2016

STUENKEL, O. New Development Banks as horizontal international bypasses: Towards a parallel order? American Journal of International Law, v. 111, p. 236-240, 2017.

STUENKEL, O. El temor hacia un mundo posoccidental. La Nación. 2016. Disponible en: http:// www.lanacion.com.ar/1944400-el-temor-hacia-un-mundo-posoccidental. Acceso el 15 jun. 2017.

SLIPAK, A. La expansión de China en el Cono Sur: horadando la integración intra-industrial argentino-brasilera. Documento de Trabajo, 2014.

THE STATE COUNCIL OF PEOPLE'S REPUBLIC OF CHINA. China's Policy Paper on Latin America and the Caribbean. The State Council of People's Republic of China. 2016. Disponible en: http:// www.fmprc.gov.cn/mfa_eng/wjdt_665385/2649_665393/t1418254.shtml. Acceso el 20 jun. 2018.

THE STATE COUNCIL OF PEOPLE'S REPUBLIC OF CHINA. China's Policy Paper on Latin America and the Caribbean. The State Council of People's Republic of China. 2008. Disponible en: http://www.gov.cn/english/official/2008-11/05/content_1140347.htm. Acceso el 20 jun. 2018.

VADELL, J. (org.). A expansão econômica e geopolítica da China no século XXI: diferentes dimensões de um mesmo processo. Belo Horizonte: Editorial PUC Minas, 2018.

XUETONG, Y. Political Leadership and Power Redistribution. Chinese Journal of Internationalc Politics, v.1, n. 9, p. 1-26, 2016.

XUETONG, Y. From Keeping a Low Profile to Striving for Achievement. The Chinese Journal of International Politics, v. 2, n. 7, p. 153-184, 2014. 